p-ISSN 2615-286X | e-ISSN 2798-5075

DOI 1052646

\title{
PENGARUH PENDIDIKAN KESEHATAN TENTANG PENYAKITBENIGNA PROSTATE HYPERPLASIA (BPH) TERHADAP PENGETAHUAN PASIEN DI RUANG BEDAH PRIA RSUD JAYAPURA
}

\author{
Aldrin Onesimus Sarauw ${ }^{1}$, Rifki Sakinah Nompo ${ }^{2}$, Arvia $^{3}$ \\ ${ }^{1)}$ Rumah Sakit Umum Daerah Jayapura \\ ${ }^{2)}$ Prodi Pendidikan Ners STIKES Jayapura \\ ${ }^{3)}$ Prodi S1 Keperawatan STIKES Jayapura \\ Email: rifkisakinahnompo@gmail.com
}

\begin{abstract}
ABSTRAK
Pendahuluan: Benigna prostate hyperplasia (BPH) adalah penyakit yang terjadi akibat penekanan pada uretra menembus prostat, sehingga menyulitkan untuk berkemih atau mengurangi kekuatan aliran urin, serta paling sering terjadi pada laki-laki berisia diatas 50 tahun akibat penuaan. Pasien biasanya datang ke rumah sakit setelah keadaan BPH semakin berat atau parah sehingga dalam pengobatannya harus dilakukan operasi. Hal ini mungkinan disebabkan ketidaktahuan masyarakat terhadap penyakit BPH yang dapat mempengaruhi derajat kesehatan. Metode Penelitian: Penelitian ini menggunakan metode Quasi Eksperimen One Group Pre Test-Post Test, dengan menggunakan uji analisa Wilcoxon. Penelitian dilakukan pada bulan Juni sampai dengan Agustus 2019. Menggunakan 30 orang sampel. Kuesioner yang digunakan berjumlah 23 item pernyataan dan telah dilakukan Uji Validitas didapatkan mean validitas = 0.624, serta Uji Reabilitas 0.935. Hasil: Tingkat pengetahuan sebelum diberikan pendidikan kesehatan tentang BPH dengan kriteria baik 1 orang (3.3\%), cukup 9 orang (30.0\%), dan kurang 20 orang (66.7\%). Tingkat pengetahuan setelah diberikan pendidikan kesehatan tentang BPH dengan kriteria baik 9 orang (30.0\%), cukup 20 orang $(66.7 \%)$, dan kurang 1 orang (3.3\%). Hasil uji pengaruh menggunakan Wilcoxon $\rho$ (Asymp. Sig. (2-tailed) $=0.000<0.05$. Kesimpulan: Peneliti menyimpulkan ada pengaruh pendidikan kesehatan tentang benigna prostate hyperplasia $(\mathrm{BPH})$ terhadap pengetahuan pasien di Ruang Bedah Pria RSUD Jayapura. Hal ini terlihat dari peningkatan yang signifikan pada tingkat pengetahuan sebelum dan setelah pendidikan kesehatan dilakukan dan diharapkan agar klien dapat meningkatkan kemampuannya dalam mencari informasi.
\end{abstract}

Kata Kunci: Benigna Prostate Hyperplasia, Pendidikan Kesehatan, Pengetahuan

\section{ABSTRACT}

Background: Benign prostate hyperplasia (BPH) is a disease that occurs pressure on the urethra through the prostate, making it difficult to urinate or reduce the strength of urine flow, and most often occurs in men aged over 50 years due to aging. Patients usually come to the hospital after the BPH condition is getting worse so surgery is the treatment patien must do. This might be happen to some people who unknow of BPH so it can be affect the health status. Research Method: This study uses the Quasi Experiment One Group Pre-Post-Test Test, using the Wilcoxon analysis test. The study was conducted in June until August 2019. Using 30 samples. The questionnaire amounted 23 statement items and the Validity Test was obtained, the mean validity $=0.624$, and the reliability test 0.935. Results: The level of knowledge before provide health education about BPH with the criteria good is 1 person (3.3\%), enough 9 people (30.0\%), and less 20 people $(66.7 \%)$. The level of knowledge after provide health education about BPH with good criteria 9 people (30.0\%), enough 20 people (66.7\%), and less 1 person (3.3\%). The test results of the influence using Wilcoxon $\rho$ (Asymp. Sig. (2-tailed) $=0,000<0.05$. Conclusions: Researchers conclude there is an effect of health education about benign prostate hyperplasia $(\mathrm{BPH})$ on the knowledge of patients in the Male Surgery Room Jayapura Hospital. This can be seen from a significant increase in the level of knowledge before and after provide health education and hoped the patien can improve his ability to seek information.

Keywords: Benigna Prostate Hyperplasia, Knowledge, Health Education 


\section{PENDAHULUAN}

Benigna prostate hyperplasia $(\mathrm{BPH})$ adalah penyakit yang terjadi akibat penekanan pada uretra menembus prostat, sehingga menyulitkan untuk berkemih atau mengurangi kekuatan aliran urin, serta paling sering terjadi pada laki-laki berisia diatas 50 tahun akibat penuaan (Prince \& Wilson, 2006; Corwin, 2009; Purnomo, 2011).

Menurut World Health Organization (WHO) terdapat sekitar 70 juta kasus degeneratif, salah satunya adalah BPH dengan insidensi di negara maju sebanyak 19\%, sedangkan di Negara berkembang sebanyak 5,35\% kasus. Kasus BPH sering ditemukan pada pria dengan usia lebih dari 65 tahun dan dilakukan pembedahan setiap tahunnya (Riskesdas, 2013). Hasil penelitian di Amerika 20\% penderita BPH terjadi pada usia 4150 tahun, 50\% terjadi pada usia 51-60 tahun dan $90 \%$ terjadi pada usia 80 tahun. Pasien biasanya datang ke rumah sakit setelah keadaan benigna prostat hiperplasia semakin berat (Nadia \& Zuhirman, 2014).

Di Indoneia BPH menjadi penyakit urologi urutan ke dua terbanyak setelah batu ginjal, pada tahun 2016 terdapat 9,2 juta kasus BPH (Riskesdas, 2013). Selain itu sepanjang kasus kejadian BPH di Rumah Sakit Indonesia bervariasi $24-30 \%$ dari kasus urologi yang dirawat di beberapa rumah sakit. Pada tahun 1994-1997, jumlah penderita benigna prostat hiperplasia di Rumah Sakit Cipto Mangunkusumo sebanyak

462. Hasan Sadikin Bandung tahun 1976-1985 sebanyak 1.185 kasus, 1993-2002 sebanyak 1.038 kasus. Di Rumah Sakit Dr. Soetomo Surabaya terdapat 1.948 kasus benigna prostat hiperplasia pada periode tahun 1993-2002 dan di Rumah Sakit Sumber Waras sebanyak 602 kasus pada tahun 1993-2002 (Rahardjo, 2013).

Benigna prostat hiperplasia akan timbul seiring dengan bertambahnya usia, sebab BPH erat kaitannya dengan proses penuaan. Penyebab BPH belum diketahui secara pasti, tetapi sampai saat ini berhubungan dengan proses penuaan yang mengakibatkan penurunan kadar hormon pria, terutama testosteron. Hormon testosteron dalam kelenjar prostat akan diubah menjadi dihidrotestosteron (DHT). DHT inilah yang kemudian secara kronis merangsang kelenjar prostat sehingga membesar. Pembentukan nodul pembesaran prostat ini sudah mulai tampak pada usia 25 tahun pada sekitar 25\% kasus (Nurmariana, 2013).
Pasien biasanya datang ke rumah sakit setelah keadaan BPH semakin berat atau dengan kasus yang parah sehingga dalam pengobatannya harus dilakukan rencana operasi. Hal ini kemungkinan disebabkan ketidaktahuan masyarakat terhadap penyakit BPH yang dapat mempengaruhi derajat kesehatan, didukung oleh pernyataan yang menyatakan bahwa bermacam pasien yang datang ke dokter, dalam keadaan darurat atau terlalu parah dan harus dilakukan tindakan pembedahan (Suharyanto \& Majid, 2013).

Pembedahan merupakan pilihan tindakan yang tepat dalam penatalaksanaan benigna prostat hiperplasia. Keputusan untuk intervensi pembedahan didasarkan pada beratnya obstruksi, adanya infeksi saluran kemih, dan perubahan fisiologi pada prostat. Salah satu tindakan pembedahan yang sering dilakukan adalah open prostatectomy/ prostatektomi terbuka yang merupakan mekanisme pengangkatan kelenjar melalui insisi abdomen. Open prostatectomy dibagi menjadi tiga yaitu prostatektomi suprapubik, prostatektomi perineal dan prostatektomi retropublik. Pasien yang telah dilakukan tindakan pembedahan bukan berarti tidak timbul masalah. Penyulit yang dapat terjadi setelah tindakan prostatektomi terbuka adalah pasien akan kehilangan darah cukup banyak, retensi urine, inkontinensia urine, impotensi dan terjadi infeksi (Purnomo, 2011).

Selain masalah setelah operasi, pengetahuan pasien tentang BPH masih belum dapat dipahami dengan jelas, hal ini terbukti dengan banyaknya angka kejadian kasus BPH di Rumah Sakit Umum Daerah Jayapura. Berdasarkan pengambilan data awal yang peneliti lakukan pada tanggal 3 hingga 5 September 2018 diketahui bahwa BPH menjadi penyakit peringkat dua, dimana angka kejadian penyakit BPH dalam tiga tahun terakhir mencapai 1.283 kasus dengan jabaran seperti berikut: pada tahun 2016 terdapat 484 kasus, 2017 terdapat 423 kasus dan pada tahun 2018 sejak bulan januari hingga agustus terdapat 376 kasus BPH, hal ini menunjukkan bahwa setiap bulannya terdapat kurang lebih 47 pasien $\mathrm{BPH}$ dan menjalani operasi.

Berdasarkan wawancara dengan tujuh orang pasien $\mathrm{BPH}$, dua orang mengatakan tidak tahu penyakit BPH harus menjalani operasi dan merasa menyesal harusnya dari dulu jika 
merasakan sakit saat berkemih segera ke rumah sakit, tiga orang mengatakan walau sudah dioperasi pasien masih belum tertalu mengerti tentang penyakit yang dialami, dan dua orang mengatakan khawatir dengan operasai yang akan dijalani serta mencari-cari tahu apa itu penyakit BPH dari tenaga kesehatan, teman dan internet.

Berdasarkan uraian tersebut peneliti tertarik untuk melakukan penelitian tentang pengaruh pendidikan kesehatan tentang penyakit benigna prostate hyperplasia terhadap pengetahuan pasien di Ruang Bedah Pria RSUD Jayapura.

\section{METODE PENELITIAN}

Jenis penelitian ini menggunakan metode Quasi Eksperimen One Group Pre Test-Post Test. Penelitian ini dilaksanakan pada bulan Juni sampai dengan Agustus 2019. Pengambilan sampel menggunakan teknik purposive sampling dengan jumlah minimal sampel 30 responden sesuai kriteria inklusi dan eksklusi.

Terdapat 3 instrumen yang digunakan dalam penelitian diantaranya: kuesioner karakteristik responden, kuesioner pengetahuan BPH, dan satuan acara penyuluhan (SAP). Kuesioner pengetahuan BPH terlebih dahulu dilakukan uji validitas menggunakan Pearson Product Moment dan reabilitas Alpha Cronbach. Dari 25 item pernyataan, didapatkan 23 item valid dan 2 item tidak valid dibuang/ didelete oleh peneliti, sehingga didapatkan rerata (mean) uji validitas $=0.624$ dan hasil uji reliabilitas $=0.935$ yang dilakukan terhadap 15 orang sampel. Analisa data menggunakan univariat dalam persentase dan bivariat menggunakan uji Willcoxon Test.

\section{HASIL PENELITIAN}

\section{Univariat}

Analisa univariat dalam penelitian ini memaparkan mengenai karakteristik responden (usia, pendidikan, pekerjaan), tingkat pengetahuan sebelum dan setelah dilakukan pendidikan kesehatan tentang BPH.

Tabel 1 Karakteristik Responden

\begin{tabular}{|c|c|c|}
\hline Karakteristik & Frekuensi & $\%$ \\
\hline \multicolumn{3}{|l|}{ Usia } \\
\hline 46-55 tahun & 2 & 6.7 \\
\hline 56-65 tahun & 8 & 26.7 \\
\hline$>65$ tahun & 20 & 66.7 \\
\hline Total & 30 & 100.0 \\
\hline
\end{tabular}

\begin{tabular}{lcc}
\hline Tidak Sekolah & 1 & 3.3 \\
SD & 8 & 26.7 \\
SMP & 9 & 30.0 \\
SMA & 11 & 36.7 \\
S1 & 1 & 3.3 \\
Total & 30 & 100.0 \\
\hline Pekerjaan & & \\
Bekerja & 19 & 63.3 \\
Tidak Bekerja & 11 & 36.7 \\
Total & 30 & 100.0 \\
\hline
\end{tabular}

Berdasarkan tabel di atas peneliti menjabarkan usia responden menurut Departemen Kesehatan tahun 2009. Dari 30 respoden yang diteliti, 2 orang atau $6.7 \%$ berusia 46-55 tahun, 8 orang atau $26.7 \%$ berusia 56-65 tahun, dan 20 orang atau $66.7 \%$ berusia $>65$ tahun. Hal ini menunjukkan bahwa sebagian besar responden berusia antara $>65$ tahun, dan paling sedikit berada pada usia 46-55 tahun.

Kriteria responden berdasarkan tingkat pendidikan. Dari 30 responden yang diteliti, 1 orang atau $3.3 \%$ tidak bersekolah, 8 orangatau $26.7 \%$ berpendidikan SD, 9 orang atau $30.0 \%$ berpendidikan SMP, 11 orang atau $36.7 \%$ berpendidikan SMA, dan 1 orang atau 3.3\% berpendidikan S1. Hal ini menunjukkan bahwa sebagian responden berpendidikan SMA dan sangat kecil responden berpendidikan S1 dan tidak sekolah.

Pada tabel 1 peneliti menjabarkan tentang karakteristik responden berdasarkan pekerjaan, dari 30 responden yang diteliti terdapat 19 orang atau $63.3 \%$ bekerja, dan 11 orang atau $36.7 \%$ tidak bekerja. Hal ini menunjukkan bahwa sebagaian besar responden memiliki pekerjaan, hal ini dilakukan karena laki-laki memiliki tanggung jawab sebagai kepala rumah tangga danpencari nafkah.

Tabel 2 Tingkat Pengetahuan Sebelum Dilakukan Pendidikan Kesehatan

\begin{tabular}{|c|c|c|}
\hline Kategori & Frekuensi & $\%$ \\
\hline Tingkat Pengeta & & \\
\hline Baik & 1 & 3.3 \\
\hline Cukup & 9 & 30.0 \\
\hline Kurang & 20 & 66.7 \\
\hline Total & $\underline{30}$ & 100.0 \\
\hline
\end{tabular}

Pada tabel 2 peneliti menggambarkan tingkat pengetahuan responden sebelum dilakukan pendidikan kesehatan. Diketahui 
dari 30 responden yang diteliti 1 orang atau $3.3 \%$ memiliki pengetahuan baik, 9 orang atau $30.0 \%$ memiliki pengetahuan cukup, dan 20 orang atau $66.7 \%$ memiliki pengetahuan kurang. Hal ini menunjukkan bahwa lebih dari sebagian responden sebelum dilakukan pendidikan kesehatan memiliki pengetahuan kurang.

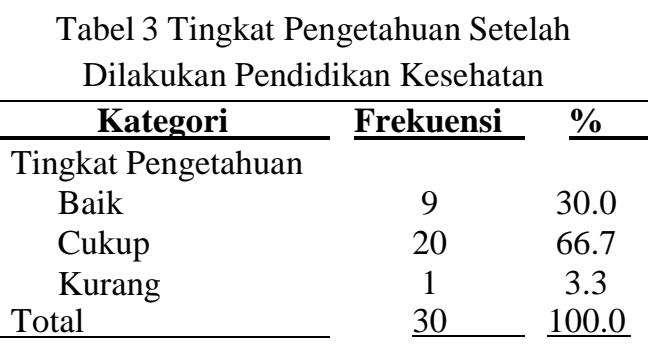

Pada tabel 3 peneliti menggambarkan tingkat pengetahuan responden setelah dilakukan pendidikan kesehatan. Diketahui dari 30 responden yang diteliti 9 orang atau $30.0 \%$ memiliki pengetahuan baik, 20 orang atau $66.7 \%$ memiliki pengetahuan cukup, dan 1 orang atau $3.3 \%$ memiliki pengetahuan kurang. Hal ini menunjukkan bahwa lebih dari sebagian responden setelah dilakukan pendidikan kesehatan memiliki pengetahuan cukup.

\section{Bivariat}

Dalam Analisa bivariat ini, peneliti menggunakan uji Wilcoxon Test untuk mengetahui pengaruh pendidikan kesehatan tentang BPH terhadap pengetahuan pasien di Ruang Bedah Pria RSUD Jayapura.

Tabel 4 Pengaruh Pendidikan Kesehatan Tentang BPH

\begin{tabular}{|c|c|c|c|}
\hline Variabel & $\begin{array}{l}\text { Mean } \\
\text { Rank }\end{array}$ & $\begin{array}{l}\text { Nilai } \\
\underline{Z}\end{array}$ & $\rho$ \\
\hline $\begin{array}{l}\text { Setelah PenKes - } \\
\text { Sebelum PenKes }\end{array}$ & $\begin{array}{l}12.61 \\
10.00\end{array}$ & $4 . \overline{-}$ & 0.000 \\
\hline
\end{tabular}

Berdasarkan tabel 4 diketahui hasil uji Wilcoxon Test didapatkan $\rho=0,000$ dengan nilai $\mathrm{Z}$ sebelum pendidikan kesehatan setelah pendidikan kesehatan $-4,260$ serta mean ranks 2.61. Hasil ini menunjukan bahwa terdapat pengaruh pendidikan kesehatan tentang BPH yang dilakukan $\rho=0,000<.005$, dengan nilai negatif -4.260 yang menunjukan adanya pengaruh pengetahuan antara sebelum dan setelah pendidikan kesehatan dengan peningkatan rata-rata pengetahuan 2.61 .

\section{PEMBAHASAN}

\section{Karakteristik Responden}

a. Berdasarkan Usia

Berdasarkan tabel 1 sebagaian besar responden berada pada rentang usia $>65$ tahun yaitu sebanyak 20 orang (66.7\%). Hal ini sesuai dengan batasan umur dari Departemen Kesehatan RI (2009) yang menyatakan bahwa umur > 65 tahun dikategorikan sebagai lansia. Menurut Murwani \& Priyantari (2011) lansia merupakan suatu perubahan perkembangan manusia yang alami. Proses penuaan ini akan terjadi pada setiap manusia yang diberikan umur panjang. Penuaan bukanlah sebuah penyakit tetapi suatu proses perkembangan manusia secara alami berupa kemunduran fisik, mental dan sosial.

Proses penuaan mempengaruhi berbagai sistem tubuh pada lansia. Seiring masa penuaan, berbagai fungsi sistem tubuh mengalami degenerasi, baik dari struktur anatomis, maupun fungsi fisiologis. Salah satu sistem tubuh yang terganggu akibat proses penuaan adalah sistem genitourinari. Pada sistem genitourinari lansia pria, masalah yang sering terjadi akibat penuaan, yakni pembesaran kelenjar prostat Benign Prostatic Hyperplasia (DeLaune \& Ladner, 2011).

Hal ini didukung oleh penelitian Parsons (2010) pembesaran kelenjar prostat, atau disebut dengan BPH (Benign Prostate Hyperplasia) merupakan salah satu masalah genitouriari yang prevalensi dan insidennya meningkat seiring dengan bertambahnya usia yang terjadi pada $70 \%$ pria berusia 60-69 tahun di Amerika Serikat, dan $80 \%$ pada pria berusia 70 tahun ke atas.

b. Berdasarkan Pendidikan

Berdasarkan tingkat pendidikan, responden terbanyak memiliki status pendidikan SMA yaitu sebanyak 11 orang (36.7\%). Pada penelitian Tamher $\&$ Noorkasiani (2011), menunjukkan 
bahwa faktor pendidikan berpengaruh terhadap fungsi kognitif seseorang yang berguna dalam menghadapi segala masalah seperti status kesehatan.

Menurut Notoatmodjo menyatakan bahwa tingkat pendidikan dapat berpengaruh pada seseorang, dimana tingkat pendidikan akan menentukan mudah atau tidaknya orang tersebut dalam menyerap dan memahami pengetahuan yang mereka peroleh, umumnya semakin tinggi pendidikan seseorang makin baik pula pengetahuannya. Seseorang dengan pendidikan yang baik, lebih matang terhadap proses perubahan pada dirinya, sehingga lebih mudah menerima pengaruh dari luar yang positif, obyektif dan terbuka terhadap berbagai informasi termasuk informasi kesehatan.

c. Berdasarkan Pekerjaan

Berdasarkan pekerjaan, dari hasil penelitian diketahui bahwa lebih dari sebagian responden masih memiliki pekerjaan yaitu sebanyak 19 orang (63.3\%). Menurut Padila (2013) sebagian para lansia masih mempunyai kemampuan untuk bekerja. Permasalahan yang timbul adalah bagaimana memfungsikan tenaga dan kemampuan lansia dalam situasi keterbatasan kesempatan kerja. Oleh sebab itu lansia yang masih berproduktif dapat dilibatkan dalam kegiatan yang mengisi waktu kosong.

Sedangkan menurut Murwani \& Priyantari (2011) terjadi perubahan berkaitan dengan pekerjaan yang akan dialami ketika masa pensiun. Tujuan ideal pensiun adalah agar para lansia dapat menikmati hari tua atau jaminan hari tua, namun dalam kenyataannya sering diartikan sebaliknya, karena pensiun sering diartikan sebagai kehilangan penghasilan, kedudukan, jabatan, peran, kegiatan, status dan harga diri.

\section{Pengaruh Pendidikan Kesehatan Tentang Benigna Prostate Hyperplasia (BPH) Terhadap Pengetahuan}

Berdasarkan hasil penelitian pada tabel

4 diketahui $\rho=0.000$ yang berarti ada pengaruh antara pendidikan kesehatan tentang BPH terhadap pengetahuan pasien. Hal ini terlihat dari peningkatan yang signifikan pada tingkat pengetahuan sebelum dilakukan pendidikan kesehatan tentang $\mathrm{BPH}$, dimana sebagian besar memiliki pengetahuan kurang 20 orang $(66.7 \%)$, sedangkan setelah dilakukan pendidikan kesehatan tentang BPH sebagian besar pengetahuan pasien meningkat menjadi cukup 20 orang $(66.7 \%)$.

Pengetahuan merupakan hasil tahu yang diperoleh melalui penglihatan ataupun pendengaran dan juga pengetahuan dipengaruhi oleh pendidikan (Wawan \& Dewi, 2011). Ada beberapa faktor yang yang mempengaruhi pengetahuan yaitu faktor umur, pengalaman, pekerjaan, lingkungan, sosial budaya, informasi dan pendidikan (Notoadmodjo, 2012).

Seseorang bisa memiliki pengetahuan tinggi jika memiliki pengetahuan yang baik serta didukung pengalaman-pengalaman dalam mengikuti kegiatan penyuluhan kesehatan seperti pendidikan kesehatan atau promosi kesehatan (Notoatmodjo, 2012). Menurut Effendy (2012) tujuan dari pemberian pendidikan kesehatan adalah agar tercapainya perubahan perilaku individu, keluarga, dan masyarakat dalam membina dan memelihara perilaku sehat dan lingkungan sehat, serta berperan aktif dalam upaya mewujudkan derajat kesehatan yang optimal.

Pada saat peneliti melakukan pendidikan kesehatan, peneliti menggunakan metode ceramah yang disertai dengan media leaflet. Peneliti menyampaikan ceramah dengan baik sehingga mampu dimengerti oleh pasien. Peneliti memilih metode ceramah ini karena lebih mudah disampaikan serta mampu dipahami dengan baik, adanya komunikasi dua arah sehingga pasien lebih memahami informasi mengenai BHP yang disampaikan oleh peneliti sehingga hal inilah dapat mempengaruhi tingkat pengetahuan pasien.

Menurut penelitian Daryanto (2013) bahwa pemilihan media presentasi yang disajikan berupa teks, gambar serta animasi yang dikombinasikan, mampu menarik perhatian seseorang dalam melaksanakan pendidikan kesehatan sehingga dapat meningkatkan pengetahuan responden. 
Pendidikan kesehatan merupakan proses perubahan perilaku individu secara dinamis, dimana perubahan tersebut bukan sekedar proses transfer pengetahuan dari seseorang ke orang lain, tetapi perubahan terjadi karena adanya kesadaran diri individu, kelompok atau masyarakat untuk mempelajarinya (Mubarak \& Chayatin, 2009).

Dalam melakukan pendidikan kesehatan tentang $\mathrm{BPH}$, peneliti menjelaskan secara singkat dan jelas mengenai pengertian, penyebab, tanda \& gejala, komplikasi, pencegahan, dan penatalaksanaan BPH. Berdasarkan pengalaman dan sebagai perawat diruang bedah, kebanyakan pasien dengan diagnosa BPH perlu dilakukan TURP (Trans Uretral Resection Prostatectomy). Menurut Purnomo (2011) TURP adalah pengangkatan sebagian atau keseluruhan kelenjar prostat melalui sitoskopi atau resektoskop yang dimasukkan melalui uretra, sehingga membuat pasien yang tidak mengetahui tentang tindakan tersebut menjadi cemas dan khawatir dengan prosedur operasi yang akan dijalani olehnya.

Tindakan TURP merupakan tindakan operasi yang dilakukan jika diagnosa BPH telah berada di stadium IV, kurangnya perhatian serta ketidaktahuan masyarakat tentang tanda \& gejala BPH membuat mereka harus menjalani operasi tersebut. Penderita BPH umumnya mengalami berbagai gejala seperti memulai fase buang air kecil yang lama dan kadang disertai mengendan, terputus-putusnya aliran urin, menetesnya urin pada akhir buang air kecil, pancaran yang lemah, dan rasa tidak puas saat buang air kecil (Giatrininggar, 2013).

Terdapat beberapa faktor risiko yang diduga dapat menyebabkan terjadinya BPH diantaranya kurang aktivitas fisik yang dapat menurunya kadar dehidrotestosteron, mengkonsumsi minuman beralkohol, dan perilaku merokok yang dapat menurunkan kadar testosteron (Setyawan., dkk, 2016).

Oleh sebab itu, perlunya peningkatan pengetahuan masyarakat tentang pencegahan penyakit BPH jauh lebih penting, agar tidak naik pada stadium lebih lanjut yang nantinya dapat menyebabkan pasien harus menjalani operasi.

\section{KESIMPULAN}

Berdasarkan hasil dan pembahasan tentang pengaruh pendidikan kesehatan tentang benigna prostate hyperplasia (BPH) terhadap pengetahuan pasien, maka dapat disimpulkan:

1. Dari hasil penelitian diketahui tingkat pengetahuan sebelum diberikan pendidikan kesehatan tentang BPH dengan kriteria baik 1 orang $(3.3 \%)$, cukup 9 orang $(30.0 \%)$, dan kurang 20 orang $(66.7 \%)$.

2. Dari hasil penelitian diketahui tingkat pengetahuan setelah diberikan pendidikan kesehatan tentang BPH dengan kriteria baik 9 orang $(30.0 \%)$, cukup 20 orang $(66.7 \%)$, dan kurang 1 orang $(3.3 \%)$.

3. Dari hasil penelitian diketahui ada pengaruh pendidikan kesehatan tentang benigna prostate hyperplasia (BPH) terhadap pengetahuan pasien di Ruang Bedah Pria RSUD Jayapura, hal ini ditunjukkan dari hasil uji Wilcoxon $\rho$ (Asymp. Sig. 2-tailed) $=0.000$ $<0.05$ yang menunjukkan adanya pengaruh yang dilakukan.

\section{DAFTAR PUSTAKA}

Corwin. (2009). Buku Saku Patofisiologi Corwin. Jakarta: Aditya Media.

Daryanto, D. (2013). Media Pembelajaran Peranannya Sangat Penting Dalam Mencapai Tujuan Pembelajaran. Yogyakarta: Gava Media.

DeLaune, S. C \& Ladner, P. K (2011). Fundamental of Nursing: Standards and Practice. Edisi 8. USA: Delmar.

Depkes RI. (2009). Profil Kesehatan Indonesia. Jakarta

Effendy, Nasrul. (2012). Dasar-dasar Keperawatan Kesehatan Masyarakat (Ed. 2). Jakarta: EGC.

Giatrininggar, E. (2013). Continuous Bladder Irrigation (CBI) Pada Klien Benigna Prostate Hyperplasia (BPH) Post Transurethral Resection Prostate (TURP) di Ruang Anggrek Tengah Kanan RSUP Persahabatan. Depok: Karya Ilmiah AkhirNers.

Mubarak, W, I \& Chayatin, N (2009). Ilmu Keperawatan Komunitas Pengantar dan Teori. Jakarta: Salemba Medika.

Murwani, A \& Priyantari, W. (2011). Gerontik Konsep Dasar dan Asuhan Keperawatan 
Home Care dan Komunitas. Yogyakarta: Fitramaya.

Nadia, F., \& Zuhirman, S. (2014). Hubungan benign prostate hypertrophy dengan disfungsi ereksi di RSUD Arifin Achmad Provinsi Riau. Jurnal Fakultas Kedokteran Universitas Riau. 2014:1(2):1-12.

Notoatmodjo, S. (2012). Promosi kesehatan dan Perilaku Kesehatan. Jakarta: Rineka cipta.

Notoatmodjo. S. (2010). Promosi Kesehatan dan Ilmu Perilaku. Jakarta: PT Rineka Cipta.

Nurmariana., Virgiandhy., \& Fitriangga, A. (2013). Gambaran karakteristik dan tingkat keparahan obstruksi pasien benign prostatic hyperplasia (BPH) di rsu dr. Soedarso pontianak. Jurnal Fakultas Kedokteran Universitas Tanjungpura Pontianak.

Padila. (2013). Buku Ajar Keperawatan Gerontik.Yogyakarta: Nuhamedika.

Parsons, J. K. (2010). Benign prostatic hyperplasia and male lower urinary tract symptoms: Epidemiology and risk factors. Springer Journal, Curr Bladder Dysfunct Rep, 5:212-218.

Prince, A. S., \& Wilson, M.. L. (2006). Patofisiologi Konsep klinis proses-proses penyakit, Ed 6, Vol 2, hal 866 - 867 dan hal 1320. Jakarta: Penerbit Buku Kedokteran: EGC.

Purnomo, B. B. (2011). Dasar-Dasar Urologi. Edisi 3 Jakarta: CV.Sagung Seto.

Rahardjo. Y. (2013). Permasalahan Bedah Urologi Pada Manula. UPG Ilmu Bedah FKUndip. Semarang.

Riset Kesehatan Dasar (Riskesdas). (2013). Badan Penelitian dan Pengembangan Kesehatan Kementerian RI tahun 2013.

Setyawan, B., Saleh, I., \& Arfan, I. (2016). Hubungan gaya hidup dengan kejadian benign prostate hyperplasia. E-Journal Universitas Muhammadiah Pontianak.

Suharyanto, T., \& Madjid, A. (2013) Asuhan Keperawatan Pada Klien Dengan Gangguan Sistem Perkemihan. Jakarta: CV.Trans Info Medika.

Tamher, S., \& Noorkasiani. (2011). Kesehatan Usia Lanjut dengan Pendekatan Asuhan Keperawatan. Jakarta: Salemba Medika.

Wawan, A., \& Dewi M. (2011). Teori dan Pengukuran Pengetahuan, Sikap, dan Perilaku Manusia. Cetakan II. Yogyakarta: Nuha Medika. 